\title{
PENGGUNAAN MULTIMEDIA INTERAKTIF FISIKA MODERN BERBASIS GAYA BELAJAR UNTUK PENGUASAAN KONSEP MAHASISWA CALON GURU
}

\author{
Ketang Wiyono \\ Program Studi Pendidikan Fisika, Fakultas Keguruan dan Ilmu Pendidikan \\ Universitas Sriwijaya Palembang \\ ketangw.fkipunsri@gmail.com
}

\begin{abstract}
ABSTRAK
Penelitian ini bertujuan untuk mengetahui penguasaan konsep mahasiswa setelah menggunakan multimedia interaktif berbasis gaya belajar yang dikembangkan. Penelitian ini menggunakan metode kuasi eksperimen. Hasil penelitian menunjukkan bahwa persentase gaya belajar terbanyak pada gaya belajar visual 48,65\% dan selanjutnya berturut-turut gaya belajar auditorial 40,549\% serta gaya belajar kinestetik $10,81 \%$. Hasil tes penguasaan konsep mahasiswa persentase skor rerata nilai pretest sebesar 39,37 mengalami peningkatan setelah dilakukan pembelajaran dengan menggunakan multimedia interaktif berbasis gaya belajar fisika modern sehingga diperoleh persentase skor rerata nilai post-test sebesar 84,97, dengan persentase $\mathrm{N}$-gain sebesar 75 dalam kategori tinggi. Hasil Ngain penguasaan konsep mahasiswa tiap gaya belajar $\mathrm{N}$-gain tertinggi diperoleh mahasiswa dengan gaya belajar auditorial sebesar 0,84 dan untuk gaya belajar visual dan kinestetik memperoleh N-gain yang sama yaitu sebesar 0,69. Hasil angket tanggapan implementasi multimedia interaktif berbasis gaya belajar fisika modern mahasiswa menyatakan bahwa 80,15\% menyatakan setuju dengan implementasi yang dilakukan. Berdasarkan hasil penelitian yang telah dilakukan disarankan agar (1) dalam mengembangkan multimedia interaktif agar mempertimbangkan karakteristik materi yaitu yang bersifat abstrak, mikroskopis dan makroskopis, (2) multimedia yang dikembangkan selain dapat mengadaptasi gaya belajar sebaiknya juga mengadaptasi perbedaan kecerdasan mahasiswa, (3) perlu kiranya di tindaklanjuti dengan mengembangkan asesmen interaktif agar dapat mengukur kemampuan mahasiswa secara autentik dan komprehensif.
\end{abstract}

Kata kunci : multimedia interaktif, gaya belajar, fisika modern

\section{PENDAHULUAN}

Fisika Modern adalah salah satu mata kuliah yang diajarkan pada program studi pendidikan fisika di LPTK. Secara umum mahasiswa perlu memperlajari Fisika Modern karena Fisika Modern menjadi dasar pengembangan teknologi saat ini. Perkembangan pesat di bidang teknologi informasi dan komunikasi dewasa ini dipicu oleh temuan di bidang Fisika Modern seperti penemuan piranti mikroelektronika yang mampu memuat banyakinformasi dengan ukuran sangat kecil (Permendiknas No. 20, 2006).

Selama ini sebagian dosen mengajarkan materi Fisika Modernhanya dengan metode ceramah dan jarang sekali melakukan kegiatan praktikum di laboratorium. Hasil studi pendahuluan menunjukkan bahwa hasil belajar Fisika Modern pada suatu LPTK dalam lima tahun terakhir masih tergolong rendah..
Rendahnya hasil belajar Fisika Modern tersebut salah satunya disebabkan kesulitan mahasiswa dalam memahami konsep-konsep Fisika Modern yang abstrak dan bersifat mikroskopis. Agar konsep-konsep Fisika Modern yang abstrak dan mikroskopis mudah dipahami oleh mahasiswa perlu adanya inovasi dalam perkuliahan fisika modern. Salah satu inovasi dalam perkuliahan yaitu dengan pengintegrasian teknologi informasi dan komunikasi dalam bentuk multimedia interaktif (Wiyono, 2009).

Sistem multimedia interaktif yang ada sekarang ini umumnya memberikan presentasi materi pembelajaran yang sama untuk setiap pengguna karena mengasumsikan bahwa karakteristik semua pengguna adalah homogen. Dalam kenyataannya, setiap pengguna mempunyai karakteristik yang berbeda-beda baik dalam hal tingkat kemampuan, gaya belajar, latar belakang atau 
yang lainnya. Seharusnya suatu sistem multimedia interaktif dapat memberikan materi pembelajaran yang tingkat kesulitannya sesuai dengan kemampuan pengguna, dan cara mempresentasikan materi pembelajarannya sesuai dengan gaya belajar pengguna. Dengan kata lain sistem multimedia interaktif seharusnya dapat mengadaptasikan tampilannya terhadap berbagai variasi karakteristik pengguna, sehingga mempunyai efektivitas pembelajaran yang tinggi (Wiyono, 2012).

Berbagai produk teknologi berbasis material magnetik dan elektronik yang bisa kita jumpai dalam kehidupan sehari-hari seperti komputer, internet, laser, GPS (global positioning system), jaringan serat optik pita lebar, tomografi komputer dan lain sebagainya adalah merupakan produk teknologi nyata dari kegiatan riset dasar fisika dalam kurun waktu 40-50 tahun terakhir. Laju lompatan yang spektakuler di bidang teknologi informasi dan komunikasi modern saat ini tidak terlepas dari gencarnya riset di bidang Fisika Modern seperti penemuan metode-metode baru dan pembuatan material semikonduktor dengan kemurnian tinggi, berbagai jenis transistor dengan kinerja tinggi, integrasi komponen menjadi chip tunggal, laser semikonduktor, media penyimpan data dengan densitas tinggi, dan lain sebagainya. Dengan kata lain, teknologi menjadi tenaga penggerak (driving force) dalam perubahan perilaku manusia dari masyarakat industri menjadi masyarakat berbasis pengetahuan dan informasi (knowledge and information based society). Tidak dipungkiri bahwa riset dasar fisika khususnya fisika modern telah banyak memberikan kontribusi nyata dalam kemajuan teknologi suatu negara yang pada gilirannya akan bermuara pada kemajuan di bidang

ekonomi sekaligus menjadi bangsa yang disegani di kancah internasional (Sembiring, 2008). Telah dilakukan penelitian sebelumnya tentang pengembangan multimedia interaktif berbasis gaya belajar sebagai inovasi media pembelajaran Fisika Modern di LPTK. Pada makalah ini akan dipaparkan hasil implementasi multimedia interaktif fisika modern berbasis gaya belajar untuk penguasaan konsep mahasiswa calon guru. Tujuan penelitian ini adalah untuk mengetahui penguasaan konsep mahasiswa calon guru setelah menggunakan multimedia interaktif berbasis gaya belajar yang telah dikembangkan.

\section{METODE PENELITIAN}

Penelitian ini menggunakan metode kuasi eksperimen dengan desain pretestposttes one group design yaitu penelitian yang dilaksanakan pada satu kelas yaitu kelas eksperimen, diawali dengan memberikan tes awal untuk mengidentifikasi kemampuan awal siswa. Kemudian dilaksanakan pembelajaran dengan menggunakan model multimedia interaktif fisika modern berbasis gaya belajar. Setelah pembelajaran selesai dilakukan tes akhir untuk mengidentifikasi peningkatan penguasaan konsep mahasiswa. Tanggapan mahasiswa dan dosen dijaring dengan angket untuk mengetahui pendapat tentang model multimedia interaktif fisika modern berbasis gaya belajar yang dikembangkan. Data yang diperoleh melalui angket dalam bentuk skala kualitatif dikonversi menjadi skala kuantitatif. Untuk pernyataan yang bersifat positif kategori SS (sangat setuju) diberi skor tertinggi, makin menuju ke STS (sangat tidak setuju) skor yang diberikan berangsur-angsur menurun. Desain penelitian dapat dilihat pada Tabel 1.

Tabel 1. Desain penelitian

\begin{tabular}{cccc}
\hline Kelas & Tes awal & Perlakuan & Tes akhir \\
\hline Eksperimen & $\mathrm{O}$ & $\mathrm{X}_{1}$ & $\mathrm{O}$ \\
\hline
\end{tabular}

Dengan $\mathrm{O}$ adalah observasi berupa tes awal dan tes akhir, $\mathrm{X}$ adalah penerapan model pembelajaran multimedia interaktif fisika modern berbasis gaya belajar. Penelitian ini dilaksanakan di LPTK Negeri Sumatera Selatan yang menyelenggarakan Program Studi Pendidikan Fisika. Subyek penelitian adalah mahasiswa calon guru fisika semester $\mathrm{V}$ yang mengikuti mata kuliah Fisika Modern. Sampel dipilih dengan teknik purposive sampling dengan jumlah 43 orang. Secara garis besar tahap-tahap penelitian ini ditunjukkan pada Gambar 1. 

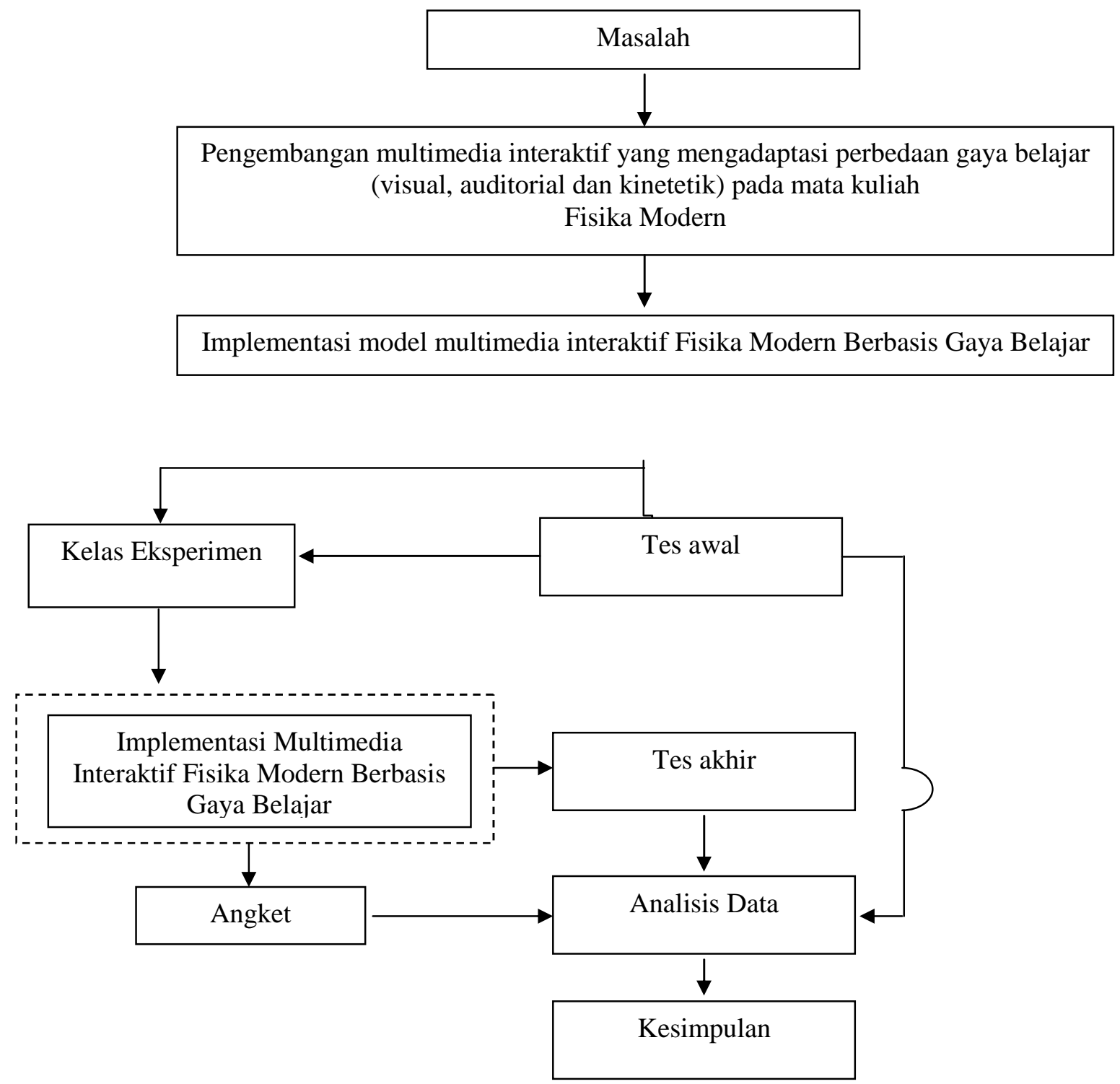

Gambar 1. Desain Penelitian

Untuk mengetahui peningkatan penguasaan konsep yang dikembangkan melalui model pembelajaran multimedia interaktif dihitung berdasarkan skor gain yang dinormalisasi. Untuk memperoleh skor gain yang dinormalisasi digunakan rumus yang dikembangkan oleh Hake (Cheng, et.al, 2004):

$$
N-\text { gain }=\frac{S_{\text {Post }}-S_{\mathrm{Pr} e}}{S_{\text {Max }}-S_{\mathrm{Pr} e}}
$$

Nilai N-gain yang diperoleh kemudian dikonsultasikan dengan Tabel 2.

Tabel 2 Klasifikasi N-gain

\begin{tabular}{cc}
\hline Kategori Perolehan $\mathbf{N}$-gain & Keterangan \\
\hline $\mathrm{N}$-gain $>0,70$ & tinggi \\
\hline $0,30 \leq N-$ gain $\leq 0,70$ & sedang \\
\hline $\mathrm{N}$-gain $<0,30$ & rendah
\end{tabular}

\section{HASIL DAN PEMBAHASAN}

Pada awal kegiatan pembelajaran dengan menerapkan model multimedia interaktif berbasis gaya belajar fisika modern mahasiswa melakukan tes gaya belajar terlebih dahulu. Hasil tes gaya belajar kemudian dikelompokkan menjadi 3 kategori gaya belajar berdasarkan jawaban mahasiswa. Hasil tes gaya belajar mahasiswa dapat dilihat seperti Gambar 2. 
JPFK, Vol. 1 No. 2, September 2015, hal 74 - 80

http://e-journal.ikippgrimadiun.ac.id/index.php/JPFK

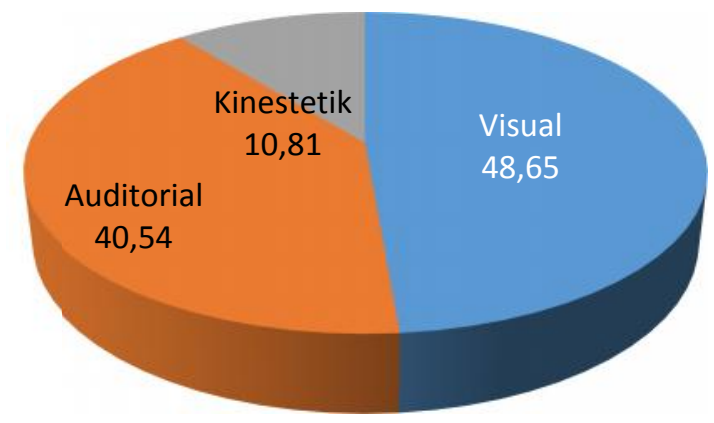

\section{Gambar 2. Profil gaya belajar mahasiswa}

Berdasarkan Gambar 2 persentase gaya belajar visual sebesar $48,65 \%$ dan selanjutnya berturut-turut gaya belajar auditorial sebesar 40,549\% serta gaya belajar kinestetik sebesar $10,81 \%$. Dari hasil tes gaya belajar ini dapat dikatakan bahwa gaya belajar mahasiswa program studi Pendidikan Fisika LPTK Negeri di Sumatera Selatan didominasi oleh gaya belajar visual. Setelah mengikuti tes gaya belajar mahasiswa akan mengikuti perkuliahan dengan menerapkan model multimedia interaktif berbasis gaya belajar fisika modern sesuai dengan gaya belajar yang dimiliki mahasiswa tersebut.

Sebelum dan sesudah dilakukan pembelajaran dengan menerapkan multimedia interaktif berbasis gaya belajar fisika modern mahasiswa diberikan tes penguasaan konsep fisika modern. Dari hasil tes awal dan akhir yang dilakukan pada pembelajaran dengan menerapkan multimedia interaktif berbasis gaya belajar fisika modern diperoleh data hasil penguasaan konsep mahasiswa yang dapat dilihat pada gambar 3 .

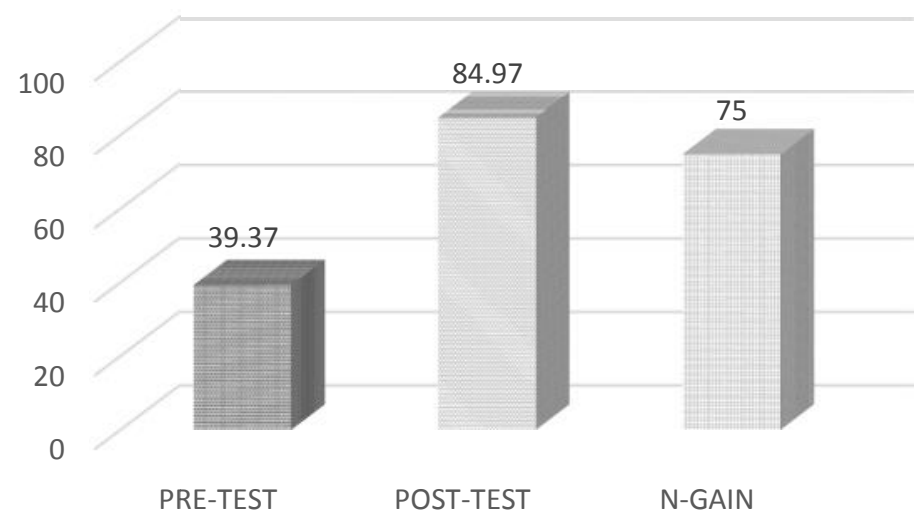

Gambar 3. Grafik perbandingan pre-test, post-test, dan N-Gain

Berdasarkan grafik pada gambar 3 dapat dilihat bahwa persentase skor rata-rata nilai pre-test sebesar 39,37 mengalami peningkatan setelah dilakukan pembelajaran dengan menggunakan multimedia interaktif berbasis gaya belajar fisika modern sehingga diperoleh persentase skor rata-rata nilai post-test sebesar 84,97. Berdasarkan data skor pre-test dan skor post-test dapat dihitung nilai $\mathrm{N}$-gain yaitu sebesar 75 dalam kategori tinggi. Dengan kategori $\mathrm{N}$-gain yang tinggi dapat dikatakan bahwa model multimedia interaktif berbasis gaya belajar fisika modern memberikan pengaruh yang besar dalam peningkatan penguasaan konsep mahasiswa pada mata kuliah fisika modern.

Pada penelitian ini tidak hanya $\mathrm{N}$-gain mahasiswa secara keseluruhan yang diperoleh, tetapi juga $\mathrm{N}$-gain dari setiap gaya belajar mahasiswa. Hasil N-gain penguasaan konsep mahasiswa tiap gaya belajar dapat dilihat pada Gambar 4. 


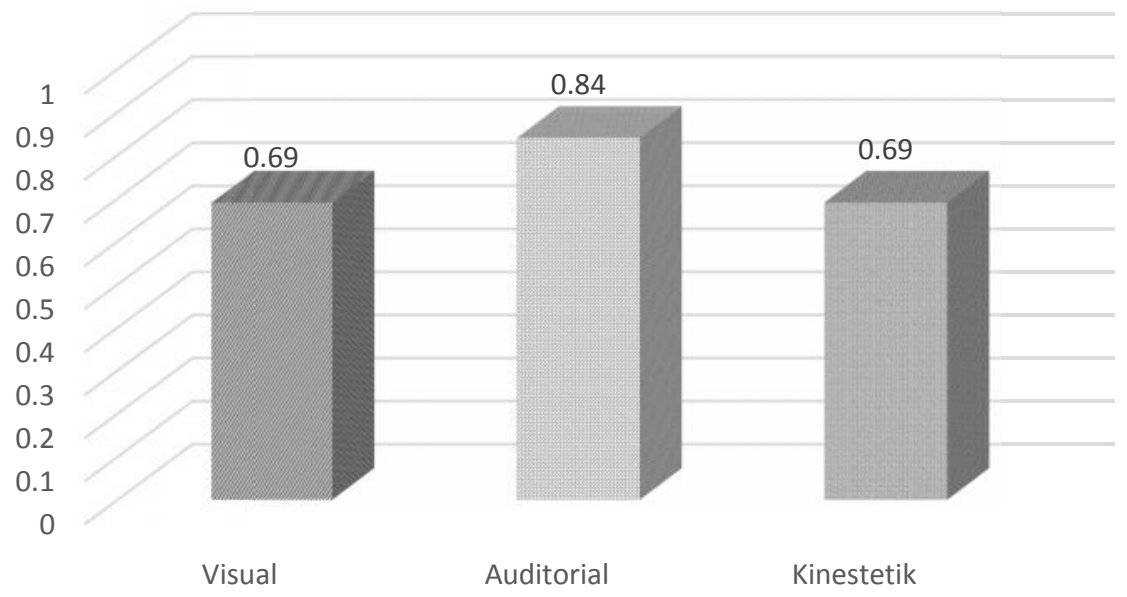

Gambar 4. Hasil N-Gain tiap gaya belajar

Berdasarkan grafik pada gambar 4 dapat dilihat bahwa hasil $\mathrm{N}$-gain tertinggi diperoleh mahasiswa dengan gaya belajar auditorial sebesar 0,84 pada kategori tinggi dan untuk gaya belajar visual dan kinestetik memperoleh $\mathrm{N}$-gain yang sama yaitu sebesar 0,69 pada kategori sedang. Hasil ini menyatakan bahwa pengaruh yang besar dalam peningkatan penguasaan konsep mahasiswa terdapat pada mahasiswa yang memiliki gaya belajar auditorial. Selain tes mahasiswa juga diberikan angket tanggapan setelah mengikuti pembelajaran dengan menerapkan multimedia interaktif berbasis gaya belajar fisika modern. Dari hasil angket tanggapan implementasi multimedia interaktif berbasis gaya belajar fisika modern mahasiswa menunjukkan bahwa $80,15 \%$ menyatakan setuju dengan implementasi yang dilakukan.

Hasil penelitian yang didapat sejalan dengan berbagai hasil penelitian pemanfaatan multimedia interaktif (MMI) dalam perkuliahan fisika telah dilakukan. MMI dalam perkuliahan fisika dasar dapat meningkatkan pemahaman konsep fisika dasar (Dori dan Belcher, 2005) meningkatkan penguasaan konsep calon guru fisika (Darmadi dkk, 2007; Gunawan dkk, 2008), mengatasi miskonsepsi fisika dasar mahasiswa (Muller \& Sharma, 2007), meningkatkan keterampilan berpikir kritis dan generik sains (Budiman dkk, 2008; Yahya dkk, 2008, Wiyono dkk, 2009).Keberhasilan MMI dalam perkuliahan fisika dasar disebabkan mahasiswa lebih aktif dan mandiri (Darmadi dkk, 2007), animasi komputer dalam MMI dapat memvisualisasikan proses-proses abstrak yang multahil dilihat atau dibayangkan (Burke, 1998), mampu menayangkan kembali informasi-informasi yang diperlukan. Penggunaan multimedia interaktif pembelajaran pada fisika lanjut sangat membantu mahasiswa dalam memahami konsep-konsep yang bersifat abstrak. Menurut McKagan (2007) mahasiswa akan lebih mudah memahami konsep mekanika kuantum yang bersifat abstrak dengan bantuan software interaktif.

Hasil tersebut juga relevan dengan hasil penelitian yang telah dilakukan oleh peneliti antara lain: Penerapan Model Pembelajara Multimedia Interaktif untuk Meningkatkan Penguasaan Konsep, Keterampilan Generik Sains dan Berpikir Kritis Siswa SMA pada Topik Relativitas Khusus (Wiyono, 2009). Model multimedia interaktif adaptif yang terdiri dari presentasi teks, audio, simulasi, animasi dengan mengadaptasi gaya belajar dapat mempermudah mahasiswa dan dosen dalam mempelajari konsep-konsep pendahuluan fisika zat padat yang bersifat abstrak dan submikroskopik (Wiyono \& Setiawan, 2012).Menurut Wiyono \& Tjiang (2011) model multimedia interaktif adaptif pendahuluan fisika zat padat (MIA-PIZA) dapat meningkatkan hasil belajar mahasiswa pada setiap gaya belajar terutama pada gaya belajar visual. Model MIA-PIZA secara signifikan dapat meningkatkan keterampilan berpikir kritis dibandingkan dengan model 
JPFK, Vol. 1 No. 2, September 2015, hal 74 - 80

http://e-journal.ikippgrimadiun.ac.id/index.php/JPFK

pembelajaran dengan bahan ajar lain (Wiyono \& Liliasari, 2012). Model Multimedia Interaktif Berbasis Gaya Belajar untuk Meningkatkan Penguasaan Konsep Pendahuluan Fisika Zat Padat (Wiyono dkk, 2012).

\section{PENUTUP}

Berdasarkan penelitian yang telah dilakukan tentang pengembangan model perkuliahan multimedia interaktif fisika modern dapat disimpulkan bahwa :

1. Multimedia interaktif fisika modern mempermudah mahasiswa dalam mempelajari konsep-konsep fisika modern yang bersifat abstrak dan mikroskopis, karena multimedia yang dikembangkan dapat mengadaptasi perbedaan gaya belajar mahasiswa.

2. Hasil penilaian ahli terhadap model yang dikembangkan rata-rata $88 \%$, dengan rekomendasi model dapat diujicobakan.

3. Hasil ujicoba terbatas menunjukkan ratarata tanggapan mahasiswa sebesar $87 \%$, hal ini menunjukkan model yang dikembangkan dapat digunakan oleh mahasiswa.

4. Hasil tes gaya belajar mahasiswa terbanyak pada gaya belajar visual $48,65 \%$ dan selanjutnya berturut-turut gaya belajar auditorial $40,549 \%$ serta gaya belajar kinestetik $10,81 \%$.

5. Hasil implementasi diperoleh persentase skor rata-rata nilai pre-test sebesar 39,37 mengalami peningkatan setelah dilakukan pembelajaran dengan menggunakan multimedia interaktif berbasis gaya belajar fisika modern sehingga diperoleh persentase skor rata-rata nilai post-test sebesar 84,97. Berdasarkan data skor pretest dan skor post-test dapat dihitung nilai n-gain yaitu sebesar 75 dalam kategori tinggi.

6. Hasil N-gain tertinggi diperoleh mahasiswa dengan gaya belajar auditorial sebesar 0,84 pada kategori tinggi dan untuk gaya belajar visual dan kinestetik memperoleh $\mathrm{N}$-gain yang sama yaitu sebesar 0,69 pada kategori sedang.

7. Hasil angket tanggapan implementasi multimedia interaktif berbasis gaya belajar fisika modern mahasiswa menyatakan bahwa $80,15 \%$ menyatakan setuju dengan implementasi yang dilakukan.

Berdasarkan hasil penelitian yang telah dilakukan perlu disarankan agar:

1. Dalam mengembangkan multimedia interaktif agar mempertimbangkan karakteristik materi yaitu yang bersifat abstrak, mikroskopis dan makroskopis.

2. Multimedia yang dikembangkan selain dapat mengadaptasi gaya belajar sebaiknya juga mengadaptasi perbedaan kecerdasan mahasiswa.

3. Perlu kiranya di tindaklanjuti dengan mengembangkan asesmen interaktif agar dapat mengukur kemampuan mahasiswa secara autentik dan komprehensif.

\section{DAFTAR PUSTAKA}

Budiman, I. dkk.(2008). Model Pembelajaran Multimedia Interaktif Dualisme Gelombang Partikel untuk Meningkatkan Pemahaman Konsep dan Keterampilan Berpikir Kritis.Jurnal Penelitian Pendidikan IPA. 2, (1), 48-55.

Cheng, K.K., et al. (2004). "Using Online Homework System Enhances Student Learning of Physics Concepts in an Introductory Physics Course". American Journal of Physics.72, (11), 1447-1453.

Darmadi, I.W. dkk.(2007). Pembelajaran Berbasis Teknologi Informasi untuk Meningkatkan Penguasaan Konsep Fisika Mahasiswa Calon Pengajar.Jurnal Penelitian Pendidikan IPA. 1, (1).

Dori, Y.J. \& Belcher, J. (2005). How Does Technology-Enable Active Learning Affect Undergraduate Student's Understanding of Electromagnetism Concept? The Journal of Learning Science.14, (2), 243-279.

Gunawan, dkk.(2008). Model Pembelajaran Berbasis Multimedia Interaktif Untuk Meningkatkan Penguasaan Konsep Calon Guru Pada Materi Elastisitas.Jurnal Penelitian Pendidikan IPA. 2, (1), 11-22. 
JPFK, Vol. 1 No. 2, September 2015, hal 74 - 80 http://e-journal.ikippgrimadiun.ac.id/index.php/JPFK

McKagan, S. B., et al. (2007). "Developing and Researching PhET Simulations For Teaching Quantum Mechanics". Physics Education Research.1, (0709), 4503 .

Muller, D.A. \& Sharma, M.D. (2007). "Tacling Misconception In Introductory Physics Using Multimedia Presentations". UniServe Science Teaching and Learning Research Proceedings.

Permendiknas No. 22. (2006). Standar Isi untuk Satuan Pendidikan Dasar dan Menengah. Jakarta: Departemen Pendidikan Nasional.

Sembiring, T. (2008).Urgensi dan kontribusi riset dasar fisika dalam bidang teknologi informasi: Efek GiantMagnetoresistance (GMR) dalam HeadRead Device. Pidato Pengukuhan Guru Besar FMIPA Universitas Sumatera Utara.

Wiyono, K \& Liliasari.(2012) Peningkatan Keterampilan Berpikir Kritis Mahasiswa Calon Guru dengan Model MIA-PIZA.Majalah Ilmiah Forum MIPA.14 (1), 10-16.

Wiyono, K. \& Agus Setiawan.(2012). Karakteristik multimedia interaktif adaptif pendahuluan fisika zat padat (MIA-PIZA).Prosiding Seminar Nasional Sains Pasca Sarjana Unesa.Surabaya: Unesa University Press. 14 Januari. pp 28-38.

Wiyono, K. \& Paulus. C. Tjiang, (2011). Profil Gaya Belajar Mahasiswa Pada Perkuliahan MIA-PIZA.Prosiding Seminar Nasional FMIPA UNESA. Surabaya: Unesa University Press. 10 Desember. pp 25-31.

Wiyono, K. dkk.(2009). Model Pembelajaran Multimedia Interaktif Realtivitas Khusus untuk Meningkatkan Keterampilan Generik Sains Siswa SMA. Jurnal Penelitian Pendidikan IPA. 3, (1), 21-30.

Wiyono, K. dkk.(2012) Model Multimedia Interaktif Berbasis Gaya Belajar untuk Meningkatkan Penguasaan Konsep PEndahuluan Fisika Zat Padat.Jurnal Pendidikan Fisika Indonesia.8 (1), 7482.

Yahya, S. dkk.(2008). Model Pembelajaran Multimedia Interaktif Optic Fisis Untuk Meningkatkan Penguasaan Konsep, Keterampilan Generik Sains Dan Keterampilan Berpikir Kritis Guru Fisika.Jurnal Penelitian Pendidikan IPA. 2, (1), 56-63. 